\title{
A Case Report of Heparin-Induced
}

Thrombocytopenia in a Patient One Month after Coronary Artery Bypass Graft Surgery in the Era of Coronavirus Disease 2019

ibrahim mungan ( $D$ imungan@gmail.com )

Saglik Bakanligi Ankara Egitim ve Arastirma Hastanesi https://orcid.org/0000-0003-0002-3643 seval izdeş

Ankara Yildirim Beyazit Universitesi Tip Fakultesi

\section{Case Report}

Keywords: Heparin-Induced Thrombocytopenia,Coronary Artery Bypass Graft, Coronavirus Disease 2019

Posted Date: June 17th, 2020

DOI: https://doi.org/10.21203/rs.3.rs-34795/v1

License: (c) (1) This work is licensed under a Creative Commons Attribution 4.0 International License.

Read Full License 


\section{Abstract}

Background : Coronavirus infectious disease 2019 (COVID-19), which evolved to a global pandemic issue leads to coagulation system abnormalities and low molecular heparin or unfractionated heparin is advised. Heparin-induced thrombocytopenia (HIT) is one of the most worried complications of heparin exposure.

Case Presentation: In this case report, we presented a 75 year- old male patient with suspicious COVID-19 infection who admitted to our intensive care unit one month after cardiac surgery. On admission due to increased D-dimer level and history of CABG, he was started to LMWH (enoxaparin) $0.5 \mathrm{mg} / \mathrm{kg}$ twice daily yet HIT occurred and enoxaparin was held. Fondaparinux was started to decrease the thrombosis risk.

Conclusion: In the era of COVID-19, the management of coagulopathy is important while HIT should be mind in every patient after the preliminary heparin treatment.

\section{Introduction}

Coronavirus infectious disease 2019 (COVID-19), which evolved to a global pandemic issue with five million cases and 340000 deaths, is characterized by hyper inflammation-related syndromes and severe acute respiratory injury $(1,2)$. The microvascular system as well as the other parts of the body is affected by inflammatory reactions and the abnormal activation of the coagulation system leads to generalized extensive micro thrombosis and small-vessel vasculitis (3). The coagulation system abnormalities and the risk of coagulation substrate depletion were suggested to be reduced by using low molecular heparin $(\mathrm{LWMH})$ or unfractionated heparin $(\mathrm{UH})$ so long as the patient's D-Dimer level returns to normal levels. The cut- off point for LMWH or UH was claimed to be $\geq 10 \mathrm{~g} / \mathrm{mL}$ for fibrin degradation product and $\geq 5$ $\mu \mathrm{g} / \mathrm{mL}$ for D-Dimer (4).

Many studies focused on the prognostic factors and predictors related to mortality in patients with COVID- 19 like increased serum ferritin, CRP, cardiac troponin, and thrombocytopenia. In critically ill patients thrombocytopenia, along with increased neutrophil count and lymphopenia or alone, was linked to an increased inflammatory response in COVID-19 patients (5). Yet the cause of thrombocytopenia could be multifactorial or other causal like Heparin-induced thrombocytopenia (HIT) (6). HIT is one of the most worried complications of heparin exposure induced by platelet factor 4 (PF4) and heparin complex recognizing platelet-activating IgG antibodies. The classical HIT type, namely Type 2 , is immunemediated while Type 1 HIT is considered as non- immune type and direct interaction between circulating platelets and heparin causes platelet sequestration and mild thrombocytopenia. Type 2 HIT occurs within 14 days of exposure but this period might be as long as 90 days (7).

Generally, the Warkentin 4 T's score which consists of the degree of reduction in thrombocyte count, thrombotic incident or sequelae, timing, and the exclusion of another reason for thrombocytopenia, is used for the clinical diagnosis of HIT (8). The incidence of HIT was reported between $0.1 \%$ and $5.0 \%$ in general population and as 1 to $2 \%$ after cardiac surgery in which the patients received UFH 
intraoperatively and postoperatively for thromboprophylaxis (9). Yet in case of infection (like COVID-19) or major surgery, negatively charged bacterial nucleic acids, and hypersulfated chondroitin could induce spontaneous HIT, in the absence of proximate heparin exposure (2).

In this case report, we presented a 75 year- old male patient with suspicious COVID-19 infection who developed HIT one month after cardiac surgery.

\section{Case Presentation}

A 75-year-old male patient with a history of hypertension, diabetes mellitus, and previous Coronary Artery Bypass Graft (CABG) surgery (one month before) was admitted to the emergency department with dyspnea and weakness. In the emergency department, transthoracic echocardiography was performed and acute cardiogenic edema and other cardiologic reasons for dyspnea were excluded. Chest computed tomography revealed unilateral peripherally ground-glass opacity which was defined with concomitant emphysematous changes. He had no fever with a maximum temperature of $37.3^{\circ} \mathrm{C}$, a respiratory rate of $18-22$ breaths per minute, a pulse of $62-88$ per minute, and blood pressure of $140 / 61 \mathrm{mmHg}$. The laboratory tests showed the results: White blood cell count $8.3^{*} 10^{9} / \mathrm{L}$, Lymphocyte $0.7 * 10^{6} / \mathrm{L}$, thrombocyte $372 * 10^{9} / \mathrm{L}$, and D-Dimer $11.28 \mathrm{mg} / \mathrm{L}$. After referral to the cardiology, pulmonology, and infectious diseases clinics, he was admitted to our intensive care unit for further investigation and management for suspicious COVID-19 infection. Coronavirus conventional polymerase chain reaction (PCR) assay for the throat swab sample based on the COVID-19 acid amplifying kids of Novel Coronavirus (2019-nCoV) Real-Time RT-PCR Kit was sent to the laboratory and hydroxychloroquine was started with a routine dose prescribed by infectious disease specialist. His symptoms were relieved on day 2 while the PCR assay was resulted as negative. On admission due to increased D-dimer level and history of CABG, he was started to LMWH (enoxaparin) $0.5 \mathrm{mg} / \mathrm{kg}$ twice daily as an anticoagulant.

On the third day of admission, platelet count started to decrease and on day five it was below $100 * 10^{9} / \mathrm{L}$. The changes in the platelet count during the intensive care unit period was illustrated in Figure 1. Urgent hematology consultation was requested and the other reasons for thrombocytopenia like hepatosplenomegaly were excluded with abdominal ultrasonography and blood smear examination. The Warkentin 4T' score (8) was found 6 and according to this score system HIT as a differential diagnosis was high probability.

Unfortunately, we could not confirm the clinical diagnosis with immunological or functional assays due to the limitations in our hospital. However the management started immediately and enoxaparin was held and fondaparinux ( $7.5 \mathrm{mg} / 0.6 \mathrm{ml}$. solution, subcutaneous, once daily) was started to decrease the thrombosis risk. 2 days after, the patient developed melena so fondaparinux ceased. No active bleeding focus on upper or lower gastrointestinal endoscopy was detected and on day 10 , thrombocyte level started to increase and melena stopped gradually. In this period there was only slight $\mathrm{Hb}$. decrease that did not accompany melena and after cardiology consultation, he was transferred to ward. 


\section{Discussion}

Thrombosis prophylaxis was advised in all COVID-19 patients unless active bleeding or thrombocytopenia and LMWH was the recommended agent for the thrombosis prophylaxis (10). Liu et al. (12) claimed that severe thrombocytopenia (platelet count less than $50 * 10^{9} / \mathrm{L}$ ) in COVID-19 was associated with mortality and it resulted from the consumptive process after endothelial damage and increased aggravation. Also, a coagulopathy mechanism was activated which lead to increased fibrin degradation and D-Dimer level (1). HIT is one of the most frequent drug-related thrombocytopenia and causes substantial morbidity unless treated appropriately. Thrombocytopenia is the main manifestation of HIT while $25 \%$ of cases are presented with venous thrombosis (11). COVID-19 infection which leads to massive inflammatory reaction and immune deregulation increases the risk of HIT yet the incidence has not been determined. New-onset thrombocytopenia 5-10 days after UH or LMWH usage should raise the suspicion of HIT in every patient especially in the era of COVID-19 (12). Hence, 4 hours after the preliminary heparin treatment, the revaluation of the platelet count and the coagulation function was advised (1).

The optimal diagnosis of HIT based on both clinical parameters and functional assays but laboratory examination is reported as time-consuming and time is critical for immediate intervention to avoid morbidity and even mortality of HIT (9). In our case, we could not confirm the clinical diagnosis of HIT functional assays due to the limitations in our hospital and this might raise suspicions about a proper diagnosis. But we believed that the increment of thrombocyte count just after the cessation of all heparin sources reinforced the diagnosis. Also, Pishko et al. (9) reported that immune assay was (+) approximately $50 \%$ of patients after cardiac surgery while the clinical HIT was seen only in $1-2 \%$ of cases. So there was a risk of overdiagnosis with immune assays and rigorous clinical assessment was advised. The functional assays which were more specific and accurate for HIT were not available in most centers (11).

Not only the discontinuation of heparin sources to decrease the amount of antibodies against PF4heparin complex but also the management of thrombosis risk by using a non-heparin anticoagulant like fondaparinux or argatroban is strongly advised unless there is a risk of bleeding (12). Fondaparinux, as a factor Xa-inhibitor, was advised in cases of HIT when other anticoagulants like argatroban were unavailable (13) and in our country, this was the issue.

Preimmunization by heparin or antigens highly similar to heparin-PF4 complexes might speed up the HIT process (12) and in our case, previous CABG surgery could be the reason for a decrease in thrombocyte account in the early period. In the present case, thrombocyte count started to drop 3 days after LMWH exposure and on day 5 it was below $100^{*} 10^{9} / \mathrm{L}$. The other manifestations of HIT like thrombosis did not occur. The other reasons for thrombocytopenia were excluded with the assistance of hematology consultation.

\section{Conclusion}


In the era of COVID-19, the management of coagulopathy is important while HIT should be mind in every patient after the preliminary heparin treatment.

\section{Abbreviation}

LMWH : Low Molecular Weight Heparin

PLT : thrombocyte count $\left(10^{9} / \mathrm{L}\right)$

\section{Declarations}

- Ethical Approval and Consent to participate: Not applicable

- Consent for publication: Written informed consent was obtained from the patient for publication of this case report and accompanying images.

- Availability of data and materials: Not applicable

- Competing interests: Not applicable

- Funding: Not applicable

- Authors' contributions: M.D. İbrahim Mungan,

Prof. Dr. Seval İzdeş,

- Acknowledgements: The authors whose names are listed above certify that they have NO affiliations with or involvement in any organization or entity with any financial interest (such as honoraria; educational grants; participation in speakers' bureaus; membership, employment, consultancies, stock ownership, or other equity interest; and expert testimony or patent-licensing arrangements), or nonfinancial interest in the subject matter or materials discussed in this manuscript.

- Authors' information: M.D. İbrahim Mungan, $\dagger$

Prof. Dr. Seval İzdeş, †

† Ankara Eğitim ve Araştırma Şehir Hastanesi, Department of Intensive Care Unit, Ankara, Turkey

\section{References}

1)Song JC, Wang G, Zhang W, et al. Chinese expert consensus on diagnosis and treatment of coagulation dysfunction in COVID-19. Mil Med Res. 2020;7(1):19. doi:10.1186/s40779-020-00247-7

2) World Health Organization (2020). Novel Coronavirus (2019-nCoV) situation reports [online]. Website: https://www.who.int/docs/default-source/coronaviruse/situation-reports/20200523-covid-19-sitrep- 
124.pdf?sfvrsn=9626d639_2 [accessed 23 May 2020].

3) Ding YQ, Bian XW. Analysis of coronavirus disease-19 (covid-19). Chin J Pathol.

2020;49(00):E003. https://doi.org/10.3760/cma.j.issn.0529-5807.2020.0003.

4) Expert Group on Novel Coronavirus Disease Clinical Treatment in Shanghai. Expert consensus on comprehensive treatment of 2019 coronavirus in Shanghai. Chin J Infect dis. 2020;1:38. https://doi.org/10.3760/cma.j.issn.1000-6680.2020.0016.

5) Ruan Q, Yang K, Wang W, Jiang L, Song J. Clinical predictors of mortality due to COVID-19 based on an analysis of data of 150 patients from Wuhan, China. Intensive Care Med. 2020;46(5):846-848. doi:10.1007/s00134-020-05991-x

6) Warkentin TE. Clinical picture of heparin-induced thrombocytopenia (HIT) and its differentiation from non-HIT thrombocytopenia. ThrombHaemost. 2016;116(5):813-22.

7) Salter B, Weiner M, Trinh M, et al. Heparin-induced thrombocytopenia: a comprehensive clinical review. J Am Col Cardiol. 2016;67:2519-32.

8) Lo GK, Juhl D, Warkentin TE, et al. Evaluation of pretest clinical score (4 T's) for the diagnosis of heparin-induced thrombocytopenia in two clinical settings. J Thromb Haemost. 2006;4(4):759-765.

9) Pishko AM, Cuker A. Heparin-Induced Thrombocytopenia in Cardiac Surgery Patients. Semin Thromb Hemost. 2017;43(7):691-698. doi:10.1055/s-0037-1602664

10) Turkey Ministry of Health (2020). COVID-19 (SARS-CoV-2 ENFEKSiYONU)(Bilim Kurulu Çalışması) [online]. Website: https://covid19bilgi.saglik.gov.tr/depo/rehberler/covid-19-rehberi/COVID-

19_REHBERI_ANTISITOKIN-ANTI_INFLAMATUAR_TEDAVILER_KOAGULOPATI_YONETIMI.pdf [accessed 07June 2020].

11) Gameiro J, Jorge S, Lopes JA. Haemodialysis-related-heparin-induced thrombocytopenia: Case series and literature review. Nefrologia. 2018;38(5):551-557. doi:10.1016/j.nefro.2018.02.010

12) Liu $X$, Zhang $X$, Xiao $Y$, et al. Heparin-induced thrombocytopenia is associated with a high risk of mortality in critical COVID-19 patients receiving heparin-involved treatment. medRxiv 2020 (In press). DOI:10.1101/2020.04.23.20076851

13) $\mathrm{He} \mathrm{Y,} \mathrm{He} \mathrm{H,} \mathrm{Liu} \mathrm{D,} \mathrm{et} \mathrm{al.} \mathrm{Fondaparinux} \mathrm{in} \mathrm{a} \mathrm{critically} \mathrm{III} \mathrm{patient} \mathrm{with} \mathrm{heparin-induced} \mathrm{thrombocytopenia:}$ A case report. Medicine (Baltimore). 2018;97(37):e12236. doi:10.1097/MD.0000000000012236

\section{Figures}




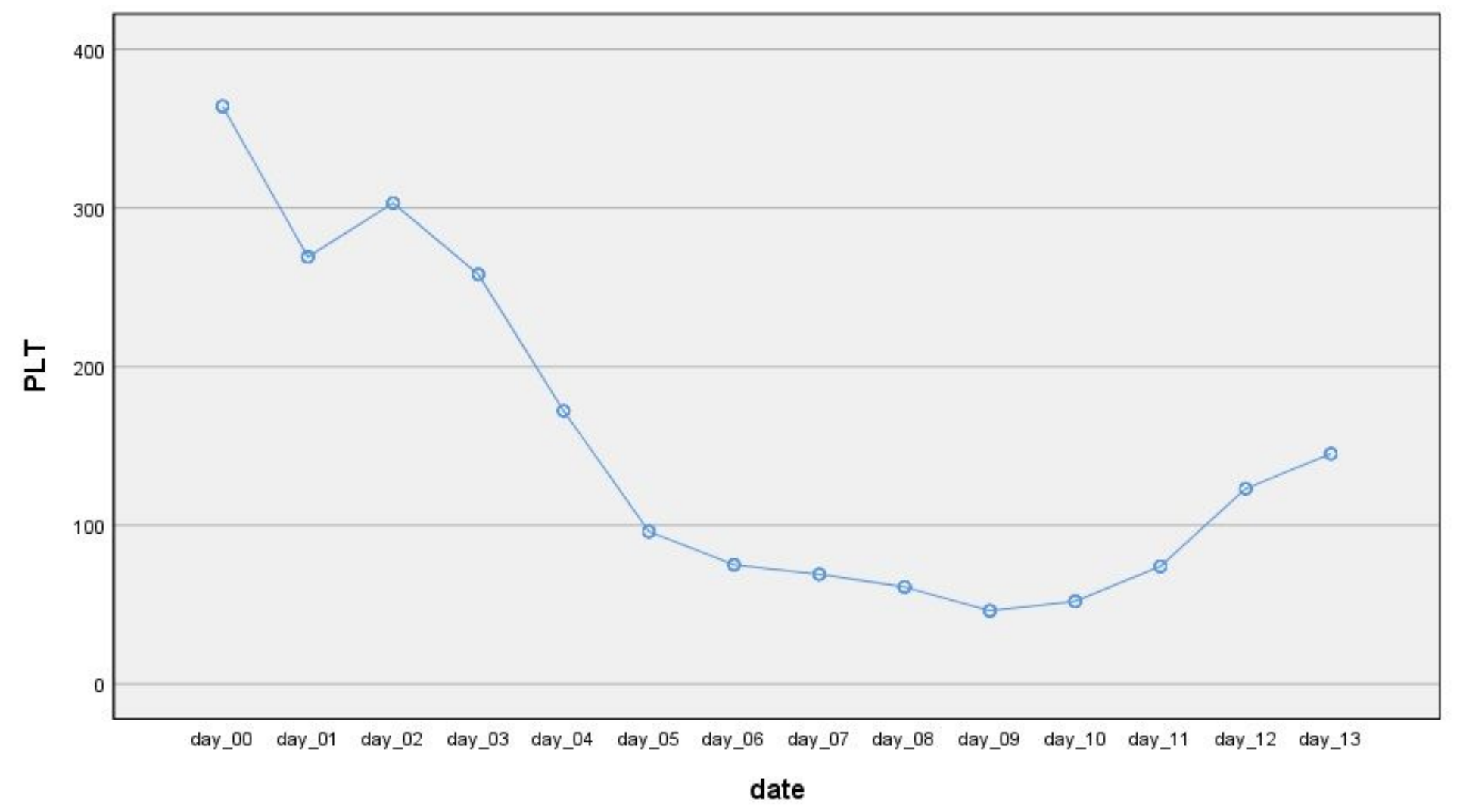

Figure 1

The thrombocyte count change after admission to intensive care unit and exposure to LMWH. 